\title{
Building Relationships between Small Manufacturing Enterprises and Vendors: Findings from the TIDE Program
}

\author{
Len Estrin
}

John Foreman

July 2003

Technology Insertion Demonstration and Evaluation

Program 
The Software Engineering Institute is a federally funded research and development center sponsored by the U.S. Department of Defense.

Copyright 2003 by Carnegie Mellon University.

NO WARRANTY

THIS CARNEGIE MELLON UNIVERSITY AND SOFTWARE ENGINEERING INSTITUTE MATERIAL IS FURNISHED ON AN "AS-IS" BASIS. CARNEGIE MELLON UNIVERSITY MAKES NO WARRANTIES OF ANY KIND, EITHER EXPRESSED OR IMPLIED, AS TO ANY MATTER INCLUDING, BUT NOT LIMITED TO, WARRANTY OF FITNESS FOR PURPOSE OR MERCHANTABILITY, EXCLUSIVITY, OR RESULTS OBTAINED FROM USE OF THE MATERIAL. CARNEGIE MELLON UNIVERSITY DOES NOT MAKE ANY WARRANTY OF ANY KIND WITH RESPECT TO FREEDOM FROM PATENT, TRADEMARK, OR COPYRIGHT INFRINGEMENT.

Use of any trademarks in this report is not intended in any way to infringe on the rights of the trademark holder.

Internal use. Permission to reproduce this document and to prepare derivative works from this document for internal use is granted, provided the copyright and "No Warranty" statements are included with all reproductions and derivative works.

External use. Requests for permission to reproduce this document or prepare derivative works of this document for external and commercial use should be addressed to the SEI Licensing Agent.

This work was created in the performance of Federal Government Contract Number F19628-00-C-0003 with Carnegie Mellon University for the operation of the Software Engineering Institute, a federally funded research and development center. The Government of the United States has a royalty-free government-purpose license to use, duplicate, or disclose the work, in whole or in part and in any manner, and to have or permit others to do so, for government purposes pursuant to the copyright license under the clause at 252.227-7013.

For information about purchasing paper copies of SEI reports, please visit the publications portion of our Web site (http://www.sei.cmu.edu/publications/pubweb.html). 


\section{Contents}

Acknowledgements .......................................................................................

Executive Summary.........................................................................................

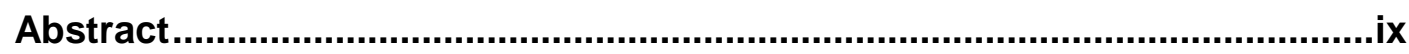

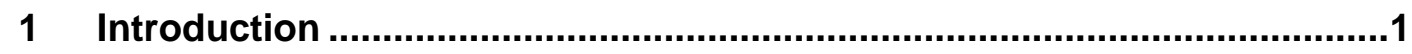

1.1 Overview of the Small Manufacturing Sector .....................................

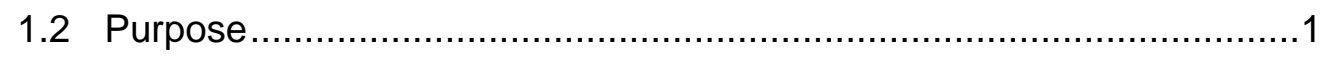

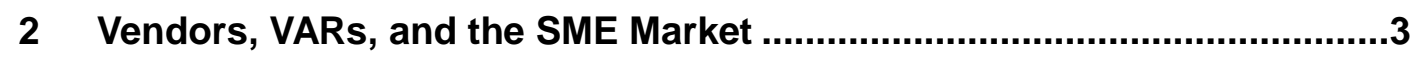

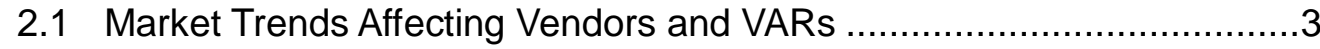

2.2 Vendor and VAR Marketing Issues .................................................

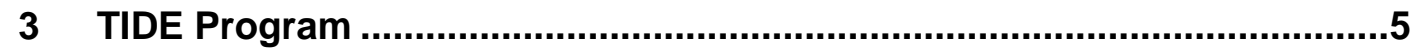

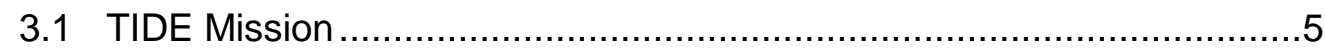

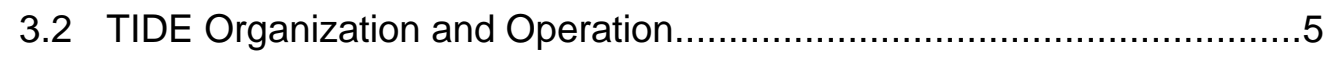

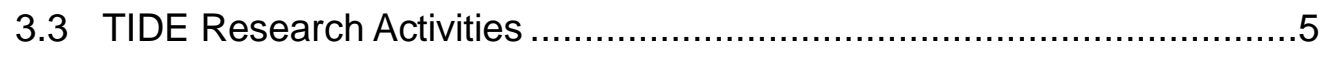

3.4 TIDE Technology Demonstration Projects.........................................

3.5 TIDE Workforce Development Activities ………...............................

3.6 TIDE Technology Development Activities ...........................................

4 Current Findings for SMEs, Vendors, and VARs ...................................11

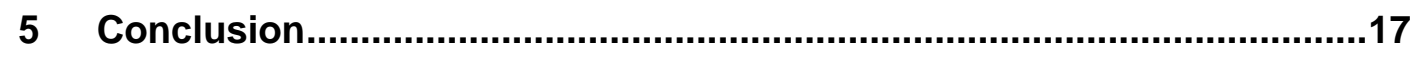

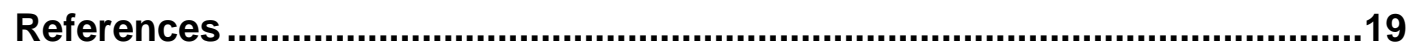


CMU/SEI-2003-TN-011 


\section{List of Tables}

Table 1: Relationship between Technology Adoption Barriers and Tide Activities .......9 


\section{Acknowledgements}

The authors gratefully acknowledge Bill Anderson, Chuck Buhman, Joe Elm, John Robert, and Fred Schenker at the Software Engineering Institute for their generous assistance in preparing this report. 


\section{Executive Summary}

Small Manufacturing Enterprises (SMEs) play a major role in the U.S. economy. According to a study by the National Association of Manufacturers (NAM), there are 329,009 small manufacturers with fewer than 500 employees (NAM 01). Many of these SMEs participate in the supply chains of large defense prime contractors. The National Coalition for Advanced Manufacturing (NACFAM) reported that in fiscal year 1999, small firms accounted for $21 \%$ of the value of prime contracts and $41 \%$ of the value of subcontracting activities for the DoD [NACFAM 02]. In addition, the NACFAM report stated that SMEs provide the surge production capacity that defense manufacturers require during times of national crisis and military build-up.

Given their importance to the economy, and the defense sector specifically, SMEs must keep pace with advances in software-based manufacturing technologies. Yet SMEs often fall behind the technology adoption curve. One reason is that vendors and value-added resellers (VARs) prefer selling to large customers. As part of its effort to help SMEs overcome technology adoption barriers, the Technology Insertion Development and Evaluation (TIDE) program at the Software Engineering Institute reviewed vendor/VAR-SME relationships in general as well as those that developed during TIDE activities. TIDE personnel also identified six principles that can contribute to a solid SME-vendor relationship and a successful implementation:

1. SMEs must be committed to technology implementation and adoption, not just purchase.

2. SMEs must view software as a strategic asset, rather than an expense.

3. SMEs and vendors/VARs must perform "due diligence."

4. Constant communication between SMEs and vendors/VARs is critical.

5. Vendors/VARs and SMEs must agree on what constitutes "proper" training and implementation.

6. SMEs may need a different type of vendor-VAR relationship than large firms. 


\section{Abstract}

Small manufacturing enterprises (SMEs) are vital to the economic and military strength of the United States. However, many SMEs struggle to keep pace with advances in softwarebased manufacturing technologies. Several factors contribute to this situation. SMEs often lack the business, process, and technical expertise to implement advanced technologies. Additionally, vendors and value-added resellers (VARs) are reluctant to target this market. For vendor/VAR-SME relationships to succeed, both parties must redefine many of the roles and rules that guide the sales process. This technical note describes activities of the Technology Insertion Development and Evaluation program at the Software Engineering Institute, and presents findings to help vendors, VARs, and SMEs develop mutually beneficial and successful relationships. 


\section{Introduction}

\subsection{Overview of the Small Manufacturing Sector}

Small Manufacturing Enterprises (SMEs) play a major role in the U.S. economy. According to a study by the National Association of Manufacturers (NAM), there are 329,009 small manufacturers in the United States with fewer than 500 employees (NAM 01). Many of these SMEs participate in the supply chains of large defense prime contractors. The National Coalition for Advanced Manufacturing (NACFAM) reported that in fiscal year 1999, small firms accounted for $21 \%$ of the value of prime contracts and $41 \%$ of the value of subcontracting activities for the DoD [NACFAM 02]. The NACFAM report stated that SMEs provide the surge production capacity that defense manufacturers require during times of national crisis and military build-up.

Despite the importance of SMEs to the defense manufacturing supply chain, indications are that SMEs are not keeping pace with advanced software technologies. For example, a white paper from the U.S. Air Force titled "Initiative for Small and Medium Enterprises" included a study of 1,002 companies. According to the study, only 35\% of companies with 50 or fewer employees had a computer-aided design and engineering capability. For companies with 50 to 499 employees, the figure rose to $51 \%$. For companies with 500 employees or more, the figure was $85 \%$ [Boden 99].

A survey of 200 SMEs in Southwestern Pennsylvania conducted by Catalyst Connection supported these findings [Mitchell 02]. The survey revealed that

- $28 \%$ have solid modeling capability

- $23 \%$ have simulation capabilities

- $16 \%$ use finite element analysis

- $30 \%$ communicate directly to suppliers and customers using the Internet

A number of factors have contributed to this situation. One factor may be the reluctance of large vendors and value-added resellers to address the small business market.

\subsection{Purpose}

This technical note describes the activities of the Technology Insertion Development and Evaluation (TIDE) program to help vendors, VARs, and SMEs develop mutually beneficial 
and successful relationships. Chapter 2 describes the relationship among large vendors and VARs and the SME market. Chapter 3 describes the TIDE program, its mission, organization, and activities. Chapter 4 provides the findings that can contribute to successful SMEvendor/VAR relationships. 


\section{Vendors, VARs, and the SME Market}

It is no secret that vendors and VARS would rather sell to large corporations than SMEs. Large firms typically purchase dozens (if not hundreds) of licenses, have the financial resources to acquire high-end products and services, and possess the in-house expertise required to train employees. Furthermore, they represent a healthy market for add-on and upgrade products.

By comparison, SMEs purchase few licenses. They often have limited financial resources and typically require and expect expensive support services. For these reasons, large vendors and VARs have traditionally avoided the SME market. Over the last several years, however, this situation has begun to change.

\subsection{Market Trends Affecting Vendors and VARs}

A number of trends are forcing vendors and VARs to modify their marketing strategies by targeting small-to-medium-sized manufacturing enterprises.

- The universe of large prospects is limited. As the number of large prospects starts to decline, vendors and VARs will need to look elsewhere for customers. Small-to-mediumsized firms represent a large, and relatively untapped, source of future sales.

- The sluggish economy is another trend that has forced vendors and VARs to look for business wherever they can find it. For example, a Computer Reseller News (CRN) survey taken in June 2002 found that $30 \%$ of enterprise solutions providers expected to increase sales by $6 \%$ over the next three months. By contrast $54 \%$ of SME solution providers expected a sales increase of $6 \%$ over the next three months [Gralla 02].

- SMEs are adopting high technologies for a number of reasons, including global competition, market pressure, and requirements from supply chain customers-especially those supply chains associated with the defense industry.

As a result of these trends, many vendors and VARs are taking a closer look at SMEs. For example, $C R N$ reported that Dell Computer has begun selling unbranded desktops to VARs [Moltzen 02]. Similarly, Sun Microsystems is trying to tap into the small-to-medium-sized business market through a new channel initiative [Kovar 02]. Both Dell and Sun have traditionally avoided approaching this market. 


\subsection{Vendor and VAR Marketing Issues}

While vendors and VARs are starting to target SMEs, serious issues exist. These include the following:

- long-term commitment of large vendors/VARs to SMEs. At this point, it is hard to determine whether vendors and VARs are committed to the SME market for the long term or whether they are just using SMEs to keep their revenue stream going until the economy rebounds. As one small reseller stated, "My concern is that they (vendors and large resellers) cherry pick, and then leave when the enterprise business picks up again. This [tactic] leaves customers feeling burned and makes it harder for us to work with those customers in the future" [Kovar 02].

- recognition of the SME environment. Research indicates that SMEs are fundamentally different than large organizations. Thong and Yap found that SMEs typically have highly centralized management structures, employ generalists rather than specialists, and suffer from "resource poverty" (e.g., financial, time, and expertise constraints) [Thong 97]. Vendors or VARs with large overhead may find it difficult to serve this environment profitably.

- interest in supporting SMEs, rather than just selling to them. SMEs often need technology adoption support. The question is, are large vendors and VARs ready to provide it? In England, for example, the government and vendors have worked together to develop Technology Means Business (TMB), an industry-standard accreditation program focused on meeting SME needs. Participants have to be re-accredited annually [Yirrell 03]. In the United States, virtually all large vendors and VARs offer product training, however they do not appear to be addressing the larger issue of technology adoption.

To summarize, vendor/VAR efforts to sell to SMEs appear to be scaled-down versions of the same approach used to sell to large corporations. In addition, questions remain about the ability of large vendors to serve, rather than sell to, this market. As a result, vendors and VARs need an unbiased source for information about SME requirements and technology adoption. The TIDE program meets this need. 


\section{TIDE Program}

The TIDE program was created through the efforts of U.S. Congressman Mike Doyle, $18^{\text {th }}$ Congressional District, Pennsylvania. Its mission is to demonstrate the cost-saving and efficiency benefits of applying commercially available software and information technologies. While TIDE is focused on SMEs that supply goods and services important to national defense, much of the work of the TIDE program is applicable to all small businesses.

\subsection{TIDE Mission}

TIDE helps SMEs adopt advanced software-based tools and capabilities by

- developing best practices for adopting software technology

- measuring the impact of investing in software technology

- performing workforce development and technology development activities

- tailoring existing technology for use by SMEs

\subsection{TIDE Organization and Operation}

The TIDE program is managed by the Software Engineering Institute $\left(\mathrm{SEI}^{\mathrm{SM}}\right)$ at Carnegie Mellon University (CMU) and coordinates the activities of a number of participants, such as the H. J. Heinz School of Management and Public Policy at CMU, the Institute for Economic Transformation at Duquesne University, the National Institute of Standards and Technology (NIST), the National Robotics Engineering Consortium, and the Southwestern Pennsylvania Industrial Resource Center (now called Catalyst Connection). TIDE personnel make every effort to take advantage of the expertise and work being performed at participating organizations and to avoid duplicating technology development efforts.

\subsection{TIDE Research Activities}

As one of the first steps in the program, TIDE staff members researched SMEs and found a number of technology adoption barriers. These included:

- Financial constraints: In many cases, SME managers felt that investing in advanced software technologies could not be justified in terms of return-on-investment (ROI) data.

${ }^{\text {SM }}$ SEI is a service mark of Carnegie Mellon University. 
In other cases, they were not sure how to control costs once they began the implementation process.

- Time constraints: The pressure of day-to-day operations, along with multiple responsibilities, left managers and employees with little time for technology adoption. Furthermore, the operating environment in smaller companies was extremely fluid. The addition or loss of just a single customer dramatically affected operations. Given thin profit margins and high overhead, cash flow was often a critical issue. As a result, SMEs focused on the short-term efforts that would generate immediate return. Issues such as long-term strategic planning and continuous technology adoption often were not "on their radar screen."

- Lack of in-house expertise: SMEs rarely had a staff of dedicated information technology (IT) professionals. Instead, they typically had one individual who was responsible for IT in general. This person usually did not have the skills or experience necessary to implement advanced engineering software.

- Issues with outside expertise: While help was available through VARs, consultants, product vendors, and industry organizations, the sheer variety of options and opinions made it difficult for SME managers to find the most appropriate help. Furthermore, much of this expertise was linked to a particular product. Therefore, such expertise and advice was considered biased. The relatively high cost of consultants also prevented SMEs from taking advantage of this resource.

- Infrastructure issues: Often, SMEs used older equipment and networks that did not provide suitable performance or capabilities.

- Cultural and organizational constraints: Cultural issues included the feeling that advanced technologies are not required or are not as cost effective as current methods. Organizational issues included overlooking the effect of advanced technologies on internal processes.

In response to these barriers, TIDE developed a three-part program of demonstration projects, workforce development activities, and technology development efforts. The body of knowledge gained through these activities can help SMEs overcome adoption barriers and implement the technologies required to support the defense industrial base. At the same time, this body of knowledge can help vendors and VARs understand the forces that are driving this market.

\subsection{TIDE Technology Demonstration Projects}

TIDE demonstration projects were performed with local SMEs. The projects documented the benefits of advanced technologies and the steps required to successfully implement them. A brief description of each demonstration project follows:

- Kurt J. Lesker Company (KJLC) manufactures ultra-high vacuum components and systems for a wide range of commercial and research applications. KJLC's management had developed a strategy to pursue very complex, high-end systems business. To achieve that goal, they decided to upgrade from a 2D mechanical drafting tool to a $3 \mathrm{D} C \mathrm{CAD}$ 
package. TIDE personnel helped them to define their needs, evaluate commercial products, and deploy the software. Based on productivity improvements, the company achieved a $100 \%$ return on its investment within 12 months.

- In another effort, TIDE personnel are working with KJLC to develop an automated production scheduling system based on software originally developed for the U.S. Air Force. The system will provide dynamic production scheduling and simulation capabilities. It will also serve as part of an integrated manufacturing execution system (MES) capable of producing bills of materials, process routings, resource management, and traceability from receipt-of-orders through shipping.

- Carco Electronics manufactures multi-axis rotational devices used to test inertial navigation and missile-seeker systems. To compete against much larger organizations, the firm needed to improve its engineering capabilities and responsiveness to customers. TIDE personnel helped the company to integrate a newly acquired FEA tool into its existing 3D CAD system and to optimize its design process to take advantage of the new software. Like KJLC, Carco Electronics achieved a 100\% return on its investment within 12 months.

- In another effort, TIDE helped Carco deploy a state-of-the-art modeling and simulation package to enhance the firm's ability to design complex digital control systems. The simulation tool included links to electronic design automation tools (EDA) that have simplified implementing the design in hardware and software.

- Magdic Precision Tool is a 20-employee job shop that both designs and manufactures compaction tooling for the powdered metal industry. Magdic wanted to reduce product delivery cycle time. To achieve this goal, it implemented an MES. The system automates quote generation, order processing and workflow management, scheduling, performance analysis, and accounting functions. Ultimately, it will enable Magdic to implement a paperless manufacturing environment complete with Web-based vendor-supplier communications.

- Internet service provider Stargate Industries and Shoptech Industrial Software Corporation are working with the TIDE program to offer online MES capabilities to small manufacturers. This effort has been designed to evaluate the application service provider (ASP) business model as a means of serving SMEs.

\subsection{TIDE Workforce Development Activities}

The TIDE program promoted workforce development through publications, training courses, and workshops. For example, the TIDE program presented a series of courses on "Foundations of Information Technology." This ten-course program presented fundamental concepts in hardware and software component selection, IT systems management, IT security, and other issues. Students who successfully completed all ten courses received a Certificate in Information Technology Management. 
TIDE also sponsored several other courses and workshops, among them:

- Concepts and Trends in Information Security and Continuous Risk Management

- Beyond the Vendor Checklist: Managing Risk in Software Technology Adoption

- Beyond Installation: Achieving Successful Software Technology Adoption

- Engineering Success for Small Enterprises

To help disseminate its growing body of knowledge, the TIDE Program sponsored TIDE Conference 2002, in Pittsburgh, PA. The papers and sessions addressed both the technical and educational barriers facing SME managers and employees. Please see the TIDE Web site (http://www.sei.cmu.edu/tide) for more information.

\subsection{TIDE Technology Development Activities}

In a third initiative, the TIDE researchers modified software tools and practices to meet SME needs. For example, the Operationally Critical Threat, Asset, and Vulnerability Evaluation ${ }^{\text {SM }}$ $\left(\mathrm{OCTAVE}^{\mathrm{SM}}\right.$ ) method was developed by the SEI to serve large organizations. Under the TIDE program, the SEI developed a modified version called $\mathrm{OCTAVE}^{\mathrm{SM}}-\mathrm{S}$ for small manufacturing enterprises. SME managers can use this tool to protect information assets, communicate business and security needs, direct and manage enterprise-wide risk assessments, and develop practice-based risk mitigation and protection strategies.

TIDE staff members also performed research into advanced engineering environments. This research can guide SME managers in developing their own technology adoption strategy and program.

The following chart shows the relationship between TIDE activities and common SME technology adoption barriers and constraints.

SM Operationally Critical Threat, Asset, and Vulnerability Evaluation and OCTAVE are service marks of Carnegie Mellon University. 
Table 1: Relationship between Technology Adoption Barriers and Tide Activities

\begin{tabular}{|c|c|c|}
\hline Barrier & Issue, Risk, Constraint & TIDE Response \\
\hline $\begin{array}{l}\text { Lack of information/ } \\
\text { expertise }\end{array}$ & $\begin{array}{l}\text { a. Unaware of software, benefits, } \\
\text { capabilities, and ROI } \\
\text { b. Lack of knowledge of how to } \\
\text { select, adopt, and implement } \\
\text { software } \\
\text { c. Lack of knowledge of how to } \\
\text { evaluate organizational needs } \\
\text { d. Lack of training in software use } \\
\text { and optimization } \\
\text { e. Lack of knowledge of outside } \\
\text { sources of expertise } \\
\text { f. Lack of strategic and tactical } \\
\text { planning skills }\end{array}$ & $\begin{array}{l}\text { a. Seven demonstration projects } \\
\text { b. TIDE courses, workshops, } \\
\text { tutorials, and presentations } \\
\text { c. Papers, publications, and } \\
\text { materials } \\
\text { d. TIDE } 2002 \text { Conference }\end{array}$ \\
\hline $\begin{array}{l}\text { Perception that SME cannot afford } \\
\text { technologies }\end{array}$ & $\begin{array}{l}\text { a. SME "cannot afford" software } \\
\text { (e.g., it is too expensive for the } \\
\text { expected return). } \\
\text { b. SME "cannot afford" technical } \\
\text { infrastructure (new computers/ } \\
\text { networks that the software } \\
\text { requires). } \\
\text { c. SME "cannot afford" training or } \\
\text { consulting. } \\
\text { d. Fear that expenses associated } \\
\text { with software will never end } \\
\text { e. Fear of wasting money on } \\
\text { software or capabilities of no use }\end{array}$ & $\begin{array}{l}\text { a. Documented ROI. } \\
\text { b. Showed how one technology } \\
\text { leads to another, and how the } \\
\text { benefits cascade through the } \\
\text { organization. } \\
\text { c. Showed how to reduce expense } \\
\text { of software by matching software to } \\
\text { needs, purchasing software that will } \\
\text { take advantage of legacy systems, } \\
\text { purchasing a mix of equipment } \\
\text { (PCs and thin clients), negotiating } \\
\text { for needed software at favorable } \\
\text { terms. }\end{array}$ \\
\hline Pressure to be productive & $\begin{array}{l}\text { a. SME does not have time (or it is } \\
\text { not worth their time) to learn about } \\
\text { software. } \\
\text { b. SME management does not have } \\
\text { time to organize and oversee } \\
\text { implementation. } \\
\text { c. SME employees do not have time } \\
\text { for training. } \\
\text { d. SME can't wait for system to } \\
\text { start paying for itself. }\end{array}$ & $\begin{array}{l}\text { a. Promoted use of seven-step } \\
\text { technology adoption process to } \\
\text { eliminate obstacles and wheel } \\
\text { spinning. } \\
\text { b. Encouraged software vendors to } \\
\text { use customer data and systems in } \\
\text { their demonstrations. } \\
\text { c. Encouraged SMEs to obtain } \\
\text { training on specific tasks and } \\
\text { applications. }\end{array}$ \\
\hline
\end{tabular}




\begin{tabular}{|c|c|c|}
\hline Barrier & Issue, Risk, Constraint & TIDE Response \\
\hline Lack of fit & $\begin{array}{l}\text { a. Organization not ready for } \\
\text { software. Employees may feel it is a } \\
\text { nuisance or waste of time. They } \\
\text { may be afraid that they will not be } \\
\text { paid or judged according to } \\
\text { previous standards. } \\
\text { b. Operations are not ready. } \\
\text { Confusion and conflict may exist } \\
\text { between departments over roles and } \\
\text { responsibilities. Business and } \\
\text { production processes may need to } \\
\text { be modified to meet software needs. } \\
\text { c. SME may not have proper } \\
\text { systems or networks. }\end{array}$ & $\begin{array}{l}\text { a. Promoted use of seven-step } \\
\text { technology adoption process to } \\
\text { eliminate obstacles and wheel } \\
\text { spinning. } \\
\text { b. Promoted use of adoption/risk } \\
\text { planning workshop to identify } \\
\text { issues, barriers, risks, and develop } \\
\text { activities to mitigate or overcome } \\
\text { them. }\end{array}$ \\
\hline
\end{tabular}




\section{Current Findings for SMEs, Vendors, and VARs}

The findings that follow represent the collective experience of TIDE program participants.

\section{SME management commitment must be obtained up front.}

The drive to adopt technology can come from a number of sources. These include the competition, supply chain partners, and internal employees. According to one VAR that participated in the TIDE program, SME engineers are particularly eager to use advanced software technologies to solve a problem or obtain a capability. Often, these engineers assume management support. As a result, they enthusiastically invite vendors/VARs to demonstrate their products only to discover that management isn't willing to pay for them. Therefore, management's commitment must be obtained before asking a vendor or VAR to invest a significant amount of time.

For example, Carco personnel wanted to implement a finite element analysis (FEA) package. However, to truly take advantage of FEA, Carco needed to upgrade its computer systems, double the capacity of its local area network, and enhance its computer-aided design capabilities. Management approved, and funded, all these efforts. It also paid for the VAR to provide in-house training on Carco applications, and retained an outside FEA service to verify employees' results during training and implementation.

TIDE finding: For an SME to successfully adopt advanced software technologies, company executives must provide sufficient funding, proper organizational and technical infrastructures, and appropriate support and training.

\section{SMEs must view software as a strategic asset, rather than as an expense.}

SMEs often turn to software (and software vendors) to eliminate a problem rather than obtain a strategic benefit. For example, the process improvement team at Magdic wanted to resolve documentation-management problems by electronically displaying and archiving their shop floor drawings. Magdic's owner contacted the TIDE program for guidance. After analyzing the company's needs, TIDE personnel recommended an MES to also help Magdic achieve its strategic business goals. This system would help improve both shop floor capacity and customer response by managing drawings, integrating business and manufacturing processes, streamlining production, and moving the company toward a paperless environment. Fully implemented, the system would enable customers to monitor order status over the Internet, freeing internal resources. 
Learning to view software as a strategic asset was not simple. TIDE personnel, vendor representatives, and company managers had to work together to examine the software in light of operational processes, management practices, and strategic objectives. In addition, implementing the MES as a strategic asset, rather than as a solution, took additional time and effort. But it has helped Magdic to

- improve responsiveness to customers

- reduce total cycle times

- streamline document management

- optimize shop scheduling

- increase shop capacity and throughput

In addition, it has forced Magdic personnel to enter complete, timely, and accurate information throughout the production process. This, in turn, has helped executive managers make better decisions. It has enabled shop floor managers to prioritize jobs and plan ahead. It has also allowed managers to quickly respond to customer requests by accessing information in real time.

Overall, it has helped Magdic increase engineering capacity 10-20\%, cut change notice processing time by $30 \%$, and significantly improve customer responsiveness.

TIDE finding: Viewing software as a strategic asset requires that vendors/VARs and SME managers work together to maximize the effect of the software throughout the entire organization. However, this effort can help eliminate obstacles and assure that the SME acquires the capabilities needed to achieve both short-term (immediate problems) and longterm (growth and evolution) goals.

\section{SMEs must be ready to both adopt advanced technologies and adapt to them.}

Adopting advanced software technologies requires a great deal of flexibility; for no matter how much a particular commercial off-the-shelf (COTS) product or application appears to fit, changes are inevitable, and the SME must make them. In the case of Magdic Precision Tooling, the company went through an exhaustive analysis of vendors to choose the most appropriate MES. Still, it had to modify the order of its business processes to match the way that the software worked.

TIDE finding: Change is part of the process of adopting COTS-based software. Instead of being viewed as an obstacle, it should be viewed as part of the continuous improvement effort required to integrate new capabilities and benefits. 


\section{SMEs, vendors, and VARs must perform "due diligence."}

For SMEs, due diligence means learning about a vendor and its capabilities by interviewing a vendor's customers, checking with trade groups about its software, reviewing magazines and vendor literature, and researching its employees, suppliers, and customers. The process also includes demanding presentations or demonstrations that reflect the company's applications and follow internal processes.

For example, TIDE and KJLC personnel set up a test system to evaluate software as part of a final sales demonstration. With TIDE and vendor representatives watching, a KLJC engineer demonstrated the prospective software. The demonstration began smoothly enough, but soon ground to a halt. The problem was with KLJC's data. An engineer had added his own notations to the files. This worked with the legacy system but the prospective software didn't recognize it. As soon as the engineer modified the notations, the software performed flawlessly. Had this event occurred during implementation, it would have cost the manufacturer and the vendor considerable time and energy. However, testing the software for "fit" early in the sales cycle avoided the situation.

For the vendors and VARs, due diligence means gathering as much information as possible on the company, how the company will use the software, how the software will affect processes within company, and what technical, organizational, and operational changes will be required to make the software work properly. Due diligence includes asking the SME's best customers for the capabilities they expect from the SME. This information can help the SME uncover new requirements and strengthen the relationship between the SME and its customers.

Due diligence offers SMEs, vendors, and VARs a number of benefits:

- It helps strengthen the vendor-SME relationship. A good relationship depends on mutual knowledge and respect.

- It helps help both parties set realistic goals and requirements. Often, vendors/VARs sell the capabilities of a product without really knowing whether those capabilities are needed. Similarly, SMEs will often require the latest "bells and whistles" without determining whether they are needed. Due diligence can identify the capabilities that the SME really "needs" rather than what the SME really "wants," thereby improving the odds of customer satisfaction.

- It can uncover and address potential problems. Confusion over system functionality, internal changes, and employee training can frustrate SMEs, VARs, and vendors alike. Truly understanding how the system will affect SME processes, employees, and customers can help assure a successful implementation. 


\section{Proper training and implementation is critical.}

SMEs involved with the TIDE program handled training in several ways. In one instance, an SME already had an employee who was familiar with 3D modeling software. This employee mentored other employees who were just learning the application. In another instance, an SME assigned an employee to read the manuals and "play" with the software. In another case, an SME sent an employee for general training, expecting that the employee could instantly apply the knowledge to the SME's specific application. To our knowledge, only one SME involved in the TIDE program hired engineers who had specific experience with the software required. Using these other approaches, it took as long as two months for employees to become productive.

On two occasions, SME employees were trained on systems that replicated their applications, operating systems, and data. Carco Electronics replicated its system at the TIDE Software Integration Laboratory. KJLC personnel used an in-house test system. Both training sessions occurred as part of final sales demonstrations. In each case, working with real data reduced the time needed to become productive by as much as $50 \%$ over similar efforts without real data.

In addition to SME training issues, Magdic found that were was a very big difference in the quality among vendor personnel. The vendor's original trainer taught Magdic employees "by the book." This led to a number of problems and delays as employees tried to perform their traditional duties. As part of its training agreement, Magdic asked for additional help. This time, the vendor sent a trainer who was a "domain expert." The trainer showed Magdic how to tailor system operations to company tasks and needs. Had the vendor provided the expert in the beginning, Magdic personnel wouldn't have wasted time struggling within the given parameters, and the vendor would have been spared the time spent answering support calls.

TIDE finding: "Canned" training presentations usually aren't specific enough to help beginning users. Any implementation plan should emphasize software training on the tasks that users perform. Also, SMEs must demand trainers who not only know the system, but who understand who will be using the system (e.g., novices or experts), and how it will be used in that specific company.

\section{SMEs may need a different type of relationship than larger firms.}

In the focus groups conducted by Duquesne University for the TIDE program, SME managers expressed their preference for a short-term and relatively low-cost relationship [Duquesne 02]. At the same time, they expected support to be available, if necessary. They also wanted the vendor or VAR to be flexible enough to "work with them."

For example, Carco performed an internal needs assessment and decided to purchase kinematics software to complement its CAD and computer-aided engineering packages. 
Carco personnel researched the vendors and their products, and settled on a particular package. (When it called the vendor, Carco found that the package was more expensive than it could easily afford.) Instead of dropping the SME and the sale, the vendor worked with Carco to address the issue and resolve it.

Not all vendors and VARs are willing or able to offer the flexibility that SMEs require. To provide these services and still make money, some VARs are looking at ASP and management service provider (MSP) business models. ASPs provide sophisticated software capabilities on a "fee-for-service" basis. MSPs offer remote monitoring and management services using the same fee-for-service model. These firms offer a high level of support, while reducing implementation costs and the need for in-house expertise. "Consulting integrators" represent another paradigm. These firms are not bound to one particular vendor or software solution; rather, they offer products to support a specific application or niche market.

TIDE finding: SMEs must realize the value of training and support services and work with the software supplier to obtain these services in a cost-effective manner. If they are unable to obtain the software and services within their budgets, they should look for an ASP, MSP, or consulting integrator. Vendors and VARs must be flexible and creative to meet SME needs. 


\section{Conclusion}

The TIDE program uses demonstration projects, workforce development activities, and technology development efforts to help SMEs overcome the barriers to adopting advanced software technologies. TIDE findings are summarized as follows:

Implementing advanced software requires a commitment from SME management to provide the funds, time, personnel, and internal changes necessary to make the project work. It also requires a commitment from employees to get behind the opportunity and a commitment from the vendors/VARs to address SME problems and issues in realistic and affordable ways.

Vendors/VARs must present their products as strategic assets, not mere short-term solutions. They must also try to understand the business of the SME, its need for the software, and the effect of their software on SME operations. In addition, they must offer products and business approaches that address the changes and challenges that arise during implementation, training, and support processes. 


\section{References}

All URLs are valid as of July 2003.

[Boden 99]

[Mitchell 02]

[Duquesne 02]

[Goodness 01]

[Gralla 02]

[Kovar 02]

[Kovar 02a]

[Moltzen 02]

[NACFAM 02]
Boden, B. Initiative for Small and Medium Enterprises. <http://www.nwlean.net/sme.htm> (1999).

Mitchell, P. \& Levine, K. "Use of Technology by Manufacturers in Southwestern Pennsylvania." Pittsburgh, PA: Catalyst Connection, 2002. <http://www.catalystconnection.org/news/manufactlandscape /TIDE.pdf $>$

Duquesne University, Institute for Economic Transformation. DoD Manufacturing Focus Group Report. Pittsburgh, PA: May 21, 2002.

Goodness, E. F. "VARs and the MSP Model: Transform and Prosper." VARBusiness. <http://www.varbusiness.com/sections /news/dailyarchives.asp?ArticleID=25760> (2001).

Gralla, P. "VARs Weigh In." VARBusiness. <http://vb.channelsupersearch.com/news/var/36856.asp> (2002).

Kovar, J. F. "Partnering Key to New Sun SMB Strategy." Computer Reseller News. <http://crn.channelsupersearch.com/news/crn /34853.asp> (2002).

Kovar, J. F. "Biggest Not Always Best." Computer Reseller News. $<$ http://crn.vnunet.com/Features/1133255> (2002).

Moltzen, E. "Channel Cautious as Dell Changes Tack." Computer Reseller News. <http://crn.vnunet.com/Analysis/1134739> (2002).

National Coalition for Advanced Manufacturing. "Contributions of and Issues Concerning Small and Medium Sized Manufacturers in the Defense Industrial Base." Washington, D.C.: NACFAM, 2002. <http://www.nacfam.org/sme_concept.pdf> 
[NAM 01]

[Thong 97]

[Yirrell 03]
National Association of Manufacturers. Today's Small and Medium Manufacturers. Washington, D.C.: November 8, 2001.

Thong, J. Y. L. \& Yap, C. S. "Effects of Resource Constraints on Information Technology Implementation in Small Business," 191-206. Proceedings of the IFIP TC8 WG8 6 International Working Conference on Diffusion, Adoption, and Implementation of Information Technology. Ambleside, Cumbria, UK, June 25-27, 1997. London, UK: Chapman and Hall, 1997.

Yirrell, S. "Unlocking the SME Market." Web Active. <http://webactive.vnunet.com/Features/1137872> (2003). 


\begin{tabular}{|c|c|c|c|c|}
\hline \multicolumn{3}{|c|}{ REPORT DOCUMENTATION PAGE } & \\
\hline \multicolumn{5}{|c|}{ 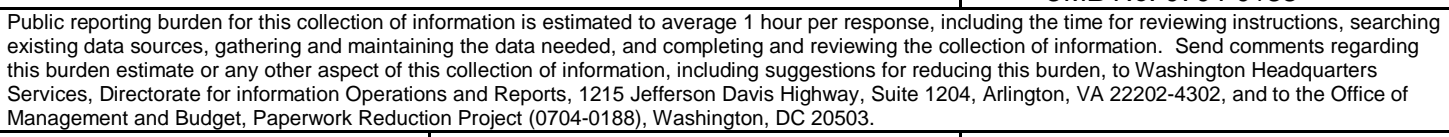 } \\
\hline $\begin{array}{l}\text { AGENCY USE ONLY } \\
\text { (Leave Blank) }\end{array}$ & \multicolumn{2}{|c|}{$\begin{array}{l}\text { 2. REPORT DATE } \\
\text { July } 2003\end{array}$} & \multicolumn{2}{|c|}{$\begin{array}{l}\text { 3. REPORT TYPE AND DATES COVERED } \\
\text { Final }\end{array}$} \\
\hline \multicolumn{3}{|c|}{$\begin{array}{l}\text { Building Relationships between Small Manufacturing Enterprises } \\
\text { and Vendors: Findings from the TIDE Program }\end{array}$} & \multicolumn{2}{|c|}{$\begin{array}{ll}\text { 5. } & \text { FUNDINGNUMBERS } \\
& \text { F19628-00-C-0003 }\end{array}$} \\
\hline \multicolumn{5}{|c|}{$\begin{array}{l}\text { 6. AUTHOR(S) } \\
\text { Len Estrin, John Foreman }\end{array}$} \\
\hline \multicolumn{3}{|c|}{$\begin{array}{l}\text { 7. PERFORMNG ORGANIZATONNAME(S) AND ADDRESS(ES) } \\
\text { Software Engineering Institute } \\
\text { Carnegie Mellon University } \\
\text { Pittsburgh, PA } 15213\end{array}$} & \multicolumn{2}{|c|}{$\begin{array}{ll}8 . & \text { PERFORMNG ORGANZATION } \\
& \text { REPORT NUMBER } \\
& \text { CMU/SEI-2003-TN-011 }\end{array}$} \\
\hline \multicolumn{3}{|c|}{$\begin{array}{l}\text { 9. SPONSOFING/MONTORING AGENCY NAME(S) AND ADDRESS(ES) } \\
\text { HQ ESC/XPK } \\
5 \text { Eglin Street } \\
\text { Hanscom AFB, MA 01731-2116 }\end{array}$} & \multicolumn{2}{|c|}{$\begin{array}{l}\text { 10. SPONSORING/MONTORING AGENCY } \\
\text { REPORT NUMBER }\end{array}$} \\
\hline \multicolumn{5}{|c|}{ 11. SUPPLEMENTARY NOTES } \\
\hline \multicolumn{3}{|c|}{$\begin{array}{l}\text { 12A DISTRIBUTIONAVALABIUTY STATEMENT } \\
\text { Unclassified/Unlimited, DTIC, NTIS }\end{array}$} & \multicolumn{2}{|c|}{ 12B DISTRABUTIONCODE } \\
\hline \multicolumn{5}{|c|}{$\begin{array}{l}\text { 13. ABSTRACT (MAXIMUM 200 WORDS) } \\
\text { Small manufacturing enterprises (SMEs) are vital to the economic and military strength of th } \\
\text { However, many SMEs struggle to keep pace with advances in software-based manufacturi } \\
\text { Several factors contribute to this situation. SMEs often lack the business, process, and tech } \\
\text { implement advanced technologies. Additionally, vendors and value-added resellers (VARs) } \\
\text { target this market. For vendor/VAR-SME relationships to succeed, both parties must redefir } \\
\text { roles and rules that guide the sales process. This technical note describes activities of the } \\
\text { Insertion Development and Evaluation Program at the Software Engineering Institute, and } \\
\text { help vendors, VARs, and SMEs develop mutually beneficial and successful relationships. }\end{array}$} \\
\hline \multicolumn{3}{|c|}{$\begin{array}{l}\text { SUBJECT TERMS } \\
\text { software technology adoption, small manufacturing enterprises, value- } \\
\text { added resellers, technology implementation, advanced software } \\
\text { integration, defense manufacturing, defense supply chains, } \\
\text { Technology Insertion Development and Evaluation (TIDE) Program }\end{array}$} & \multicolumn{2}{|c|}{$\begin{array}{l}\text { 15. NUMBER OF PAGES } \\
30\end{array}$} \\
\hline \multicolumn{5}{|c|}{ 16. PRICECODE } \\
\hline $\begin{array}{l}\text { 17. SECURTY CLASSIACATION } \\
\text { OF REPORT } \\
\text { Unclassified }\end{array}$ & $\begin{array}{l}\text { 18. SECURTY CLASSIFCATIONOF } \\
\text { THS PAGE } \\
\text { Unclassified }\end{array}$ & $\begin{array}{l}\text { 19. SECURTYY CLAC } \\
\text { ABSTRACT } \\
\text { Unclassifie }\end{array}$ & SIFCATIONOF & $\begin{array}{l}\text { 20. LMTATION OF ABSTRACT } \\
\text { UL }\end{array}$ \\
\hline
\end{tabular}

